\title{
High Cycle Fatigue Property and Micro Crack Propagation Behavior in Extruded AZ31 Magnesium Alloys
}

\author{
Yasuo Ochi ${ }^{1}$, Kiyotaka Masaki ${ }^{1}$, Toru Hirasawa ${ }^{1, *}$, Xiaorui $\mathrm{Wu}^{1, *}$, \\ Takashi Matsumura $^{1}$, Yorinobu Takigawa ${ }^{2}$ and Kenji Higashi ${ }^{2}$ \\ ${ }^{1}$ Department of Mechanical Engineering \& Intelligent Systems, University of Electro- Communications, \\ Tokyo (UEC, Tokyo), Tokyo 182-8585, Japan \\ ${ }^{2}$ Department of Materials Science, Graduate School of Engineering, Osaka Prefecture University, Osaka 599-8531, Japan
}

High cycle fatigue tests in rotating bending loading were carried out in extruded AZ31 magnesium alloys with two kinds of grain size (about $30 \mu \mathrm{m}$ and about $50 \mu \mathrm{m}$ ). Effects of microstructure and grain size on fatigue behaviors such as fatigue strength, crack initiation and propagation behaviors were discussed. As the results, there were no clear difference in the fatigue strength, the crack initiation and propagation behaviors in the both alloys. There showed a clear bending point in the relation between crack propagation rate $\mathrm{d} a / \mathrm{d} N$ and the stress intensity factor range $\Delta K$ at about $\Delta K=3 \mathrm{MPa} \sqrt{m}$. The fatigue lives in the higher stress level were evaluated from the inclusion size and the relation of $\mathrm{d} a / \mathrm{d} N-\Delta K$.

(Received December 1, 2005; Accepted March 14, 2006; Published April 15, 2006)

Keywords: magnesium alloy, high cycle fatigue, crack initiation, crack propagation, microstructure, fatigue life evaluation

\section{Introduction}

As magnesium alloys are very attractive materials because of their extreme light weight, high specific strength and stiffness, and good recycling property, then, they have recently been increasing applications for various electric machinery such as portable computers and handy telephones. ${ }^{1)}$ Nowadays, they are also expected as components materials as automobile parts due to their energy and weight saving characteristics. For applications of magnesium alloys to structural components, it is necessary to accumulate many fatigue data. ${ }^{2-9)}$

In many magnesium alloys, it is well known that AZ31 magnesium alloys show the higher specific strength and the higher ductility with grain refining and grain orientation controlling by ECAP (equal channel angular pressing) method, ${ }^{10)}$ and the researches for effects of grain refining on the fatigue property have been performed. ${ }^{6-8)}$ Usually, many steels and irons show the increasing the static strength and the fatigue strength by grain refining in according to Hall-Petch relation. However, it has been not clear that the relation between the grain size and the fatigue strength in magnesium alloys.

In the present study, high cycle fatigue tests in rotating bending loading have been carried out using extruded AZ31 magnesium alloys with two kinds of grain size in laboratory air at room temperature. Effects of microstructures, inclusions and grain sizes on fatigue properties such as fatigue strength, crack initiation and propagation behaviors have been discussed experimentally. And an estimation of fatigue lives in higher stress levels has also been investigated from relations between inclusion sizes and the crack propagation rate relation of $\mathrm{d} a / \mathrm{d} N-\Delta K$.

*Graduate Student, University of Electro-Communications, Tokyo (UEC, Tokyo), Tokyo 182-8585, Japan
Table 1 Chemical composition of AZ31 alloy (mass\%).

\begin{tabular}{ccccccccc}
\hline $\mathrm{Al}$ & $\mathrm{Zn}$ & $\mathrm{Mn}$ & $\mathrm{Fe}$ & $\mathrm{Si}$ & $\mathrm{Cu}$ & $\mathrm{Ni}$ & $\mathrm{Ca}$ & $\mathrm{Mg}$ \\
\hline $2.5-3.5$ & $0.50-1.5$ & $0.2 \sim$ & $\sim 0.03$ & $\sim 0.10$ & $\sim 0.10$ & $\sim 0.005$ & $\sim 0.04$ & Bal.
\end{tabular}

\section{Experimental Procedure}

\subsection{Materials}

The material used in the study is a commercial extruded magnesium alloy AZ31. Table 1 shows the chemical composition in JIS H4201 standard in the present alloy. The material was provided in as-extruded condition of $16 \mathrm{~mm}$ in diameter, and one material was used as-received condition, and the other was used as heat-treated condition of furnace cooling after heating at $400^{\circ} \mathrm{C}$ for $100 \mathrm{~h}$ keeping. The average grain size of the first one and the second one are 29 and $47 \mu \mathrm{m}$, respectively, and then, the materials are referred as the AZ31-30 and the AZ31-50, respectively. Figure 1 shows microstructures in parallel plane to the extruded direction of the two magnesium alloys. Table 2 shows mechanical properties of the materials. The static strength of the AZ3130 is a little higher than those of the AZ31-50, however, the difference is very small.

\subsection{Fatigue tests}

As shown in Fig. 2, fatigue specimens of round bar type with dull notch on the center (a stress concentration factor 1.05) were machined from the extruded materials of $16 \mathrm{~mm}$ in diameter. The central part was wet-polished with emery paper of \#2000 contained kerosene oil, and after that, was finished with buff polishing.

Rotating bending fatigue tests were carried out in conditions of frequency $2760 \mathrm{rpm}$ at the stress Ratio $R=$ -1.0 . It has been reported that the fatigue property of magnesium alloys were affected by humidity in atmosphere environment, ${ }^{5)}$ however, in the present study the fatigue tests 

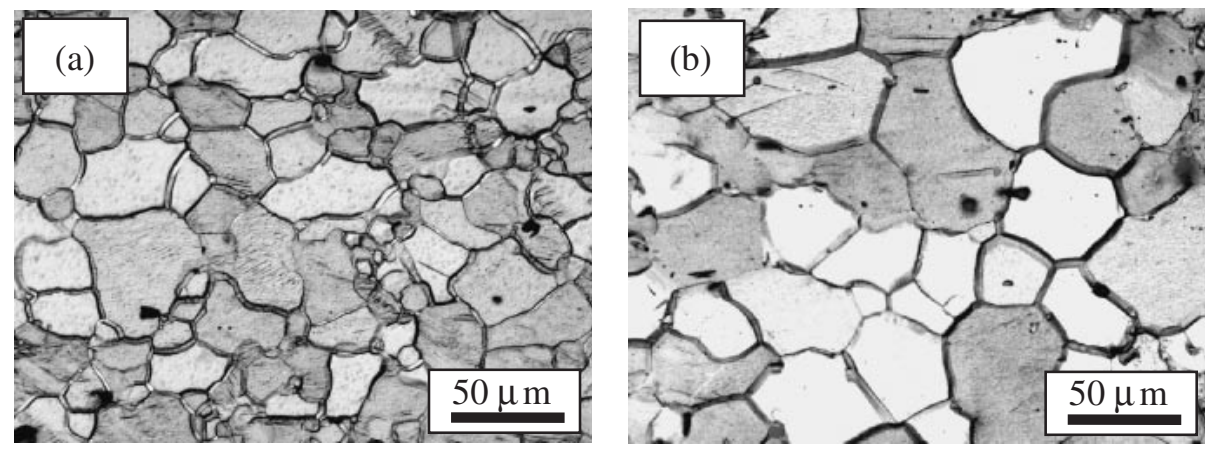

Fig. 1 Microstructures of AZ31-30 and AZ31-50 alloys.

Table 2 Mechanical property of AZ31 alloy.

\begin{tabular}{cccccc}
\hline Specimen & $\begin{array}{c}\text { Young's } \\
\text { modulus, } \\
E / \mathrm{GPa}\end{array}$ & $\begin{array}{c}\text { Tensile } \\
\text { strength, } \\
\sigma_{\mathrm{B}} / \mathrm{MPa}\end{array}$ & $\begin{array}{c}0.2 \% \text { Proof } \\
\text { stress, } \\
\sigma_{0.2 \%} / \mathrm{MPa}\end{array}$ & $\begin{array}{c}\text { Elongation } \\
(\%)\end{array}$ & $\begin{array}{c}\text { Vickers } \\
\text { Hardness } \\
\text { Hv }\end{array}$ \\
\hline AZ31-30 & 39 & 270 & 203 & 17 & 60 \\
AZ31-50 & 38 & 250 & 184 & 22 & 50 \\
\hline
\end{tabular}

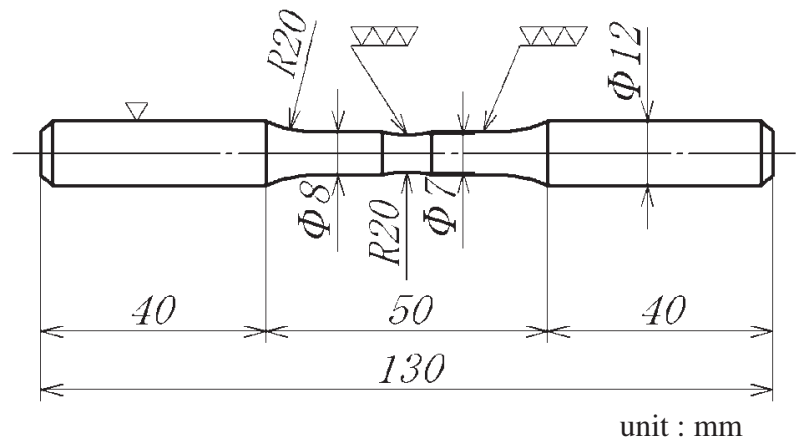

Fig. 2 Shape and dimension of the fatigue test specimen ( $\mathrm{mm})$.

were carried out in laboratory air (temperature $16-25^{\circ} \mathrm{C}$, humidity $40-70 \%$ ) because of studying the basic property of fatigue in magnesium alloys in general environment. The fatigue tests were stopped at the cycles of $10^{7}$ cycles, and the strength at $10^{7}$ cycles was defined as a fatigue limit. Observations of surface cracks behaviors were made using replication technique and an optical microscope. Fracture surface were observed after the tests by a field emission type scanning electron microscope (FE-SEM) in order to specify crack initiation sites and to discuss fracture morphology.

\section{Experimental Results}

\subsection{Fatigue test results}

Figure 3 shows S-N diagrams in two alloys. From the diagrams there were no clear difference in fatigue lives in all regime, and the fatigue limit at $10^{7}$ cycles were about $110 \mathrm{MPa}$ in both alloys. These results were assumed that the difference in grain sizes of both alloys was small.

\subsection{Observations results of fracture surface}

Figures 4 and 5 show an example of observation results of fracture surface in the AZ31-30 and AZ31-50 at the stress

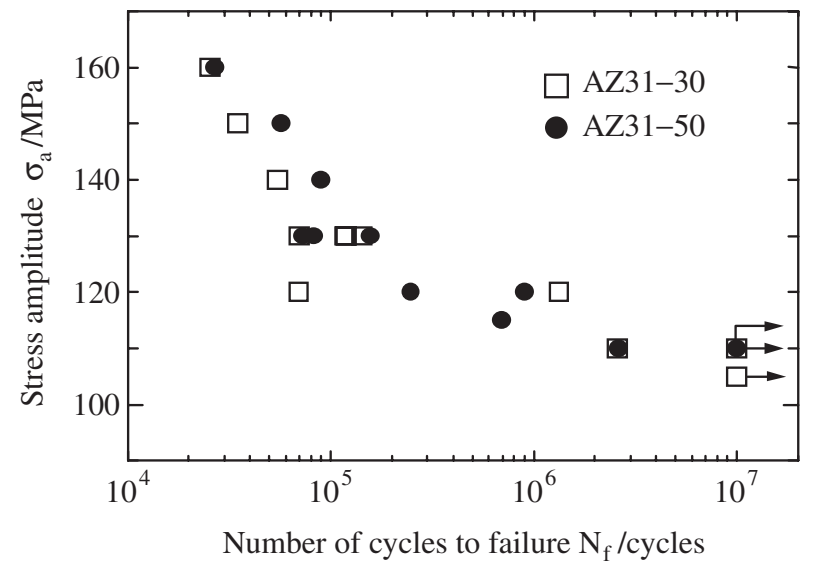

Fig. 3 S-N diagram of AZ31-30 and AZ31-50 alloys.

amplitude of $130 \mathrm{MPa}$, respectively. Figures 4(a) and 5(a) shows the low magnification images and Figs. 4(b) and 5(b) shows the high magnification images near the fracture origin site, respectively. From the observation results, the fracture occurred on inclusions near surface in all cases. In the present study, composition analysis was not performed, however, it is assumed that the inclusions are $\mathrm{Mg}-\mathrm{Al}-\mathrm{Zn}$ system $\left(\mathrm{Mg}_{23}(\mathrm{Al}, \mathrm{Zn})_{49}\right)$ or $\mathrm{Mg}-\mathrm{Al}$ system $\left(\mathrm{Mg}_{17} \mathrm{Al}_{12}\right)$ from the report by Z. Y. Nan et al. ${ }^{9 \text { ) }}$

There showed the intense rough morphology near crack initiation sites of fracture surface in both alloys, and the rough area was about $500 \mu \mathrm{m}$ in depth from the crack origin sites. And then, they showed comparably flat surface morphology after the rough region.

\subsection{Surface crack propagation behaviors}

In order to investigate the surface crack propagation behaviors, the replication technique method has been performed. The two numbers of specimens for the observation of surface crack propagation behaviors were fatigued at the stress amplitude of $130 \mathrm{MPa}$ for both alloys, respectively. Figure 6 shows the relation between the crack length $2 a$ of main cracks and the relative number of cycles to fracture cycles $N / N_{\mathrm{f}}$ for two specimens in both alloys. From the figures, the crack propagation curves showed almost similar tendency in both alloys. Plural number of cracks occurred at each specimen, but crack didn't coalesce each other during the fatigue process and each main crack propagated individ- 

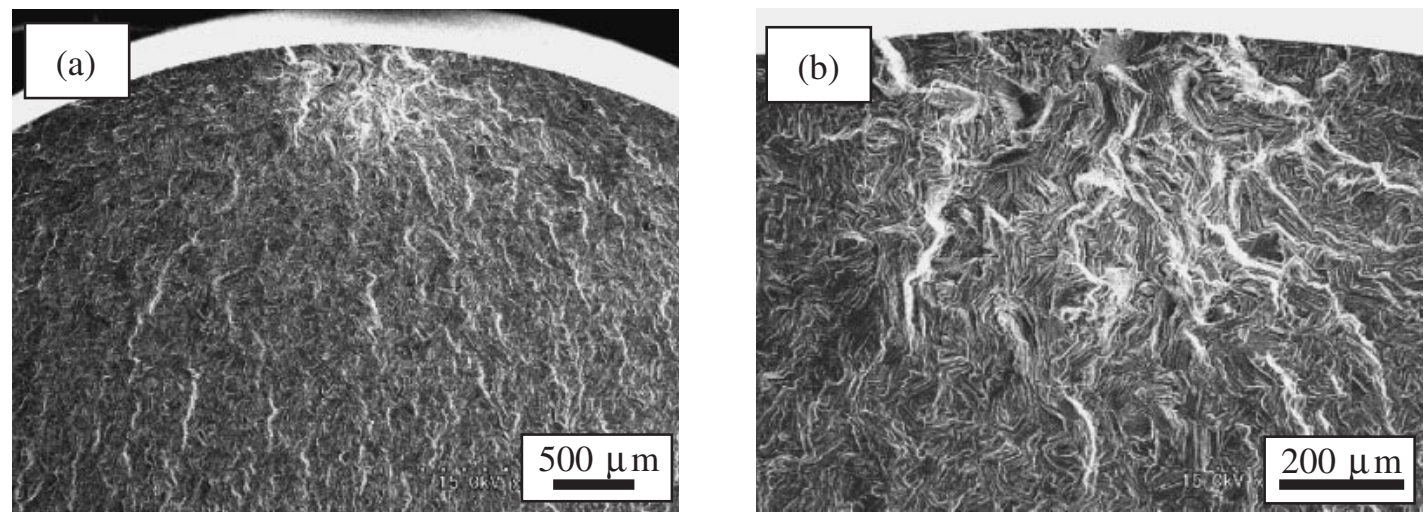

Fig. 4 Fracture surface of AZ31-30 alloy.
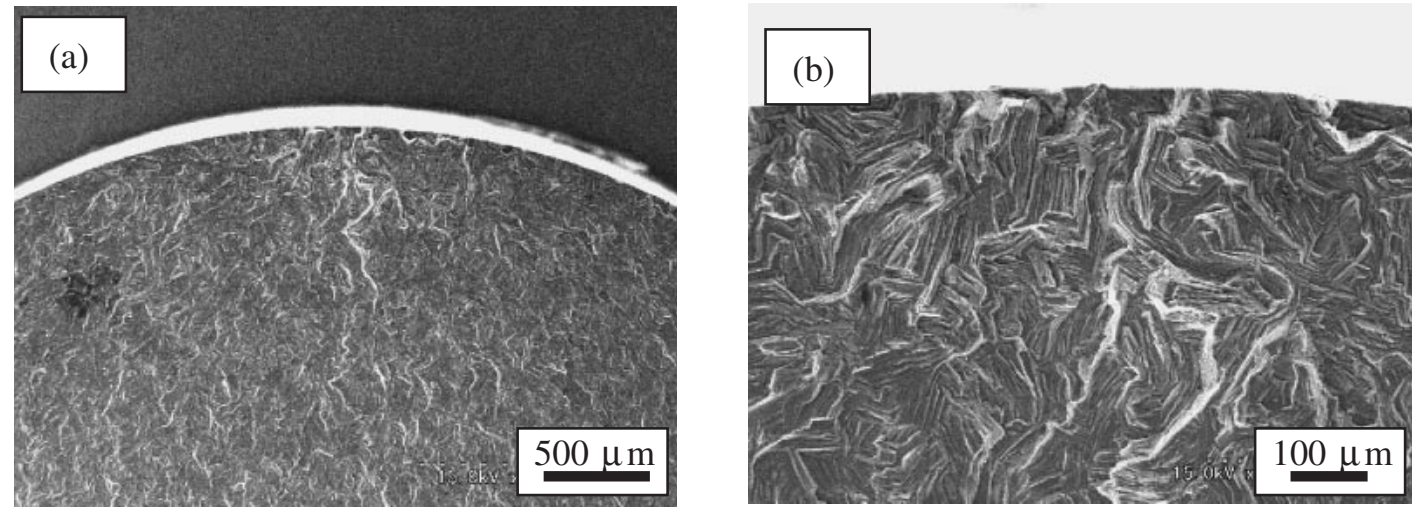

Fig. 5 Fracture surface of AZ31-50 alloy.

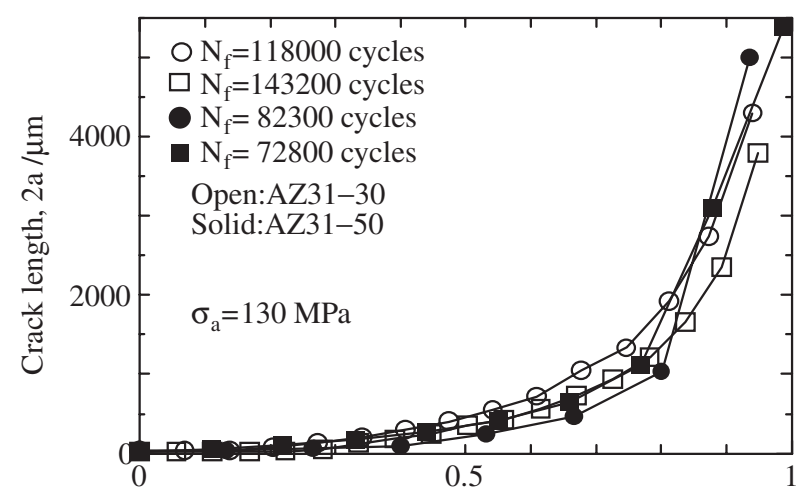

Relative number of cycles $\mathrm{N} / \mathrm{N}_{\mathrm{f}}$

Fig. 6 Relation between crack length $2 a$ and ratio of number of cycles to failure $N / N_{\mathrm{f}}$.

ually. The cracks initiated at very early stage from inclusions near surface in both alloys, but they propagated very slowly during the early stage. The relative number of cycles to reaching about $500 \mu \mathrm{m}$ was almost the half life in both alloys.

Furthermore, the size distribution of inclusions which crack initiated by the replication observation results are shown in Fig. 7. From the figure, the inclusion sizes were distributed about 20 to $55 \mu \mathrm{m}$ at the surface, then the maximum size of inclusions was about $50 \mu \mathrm{m}$ and the crack initiated sites was assumed to be these size of inclusions.

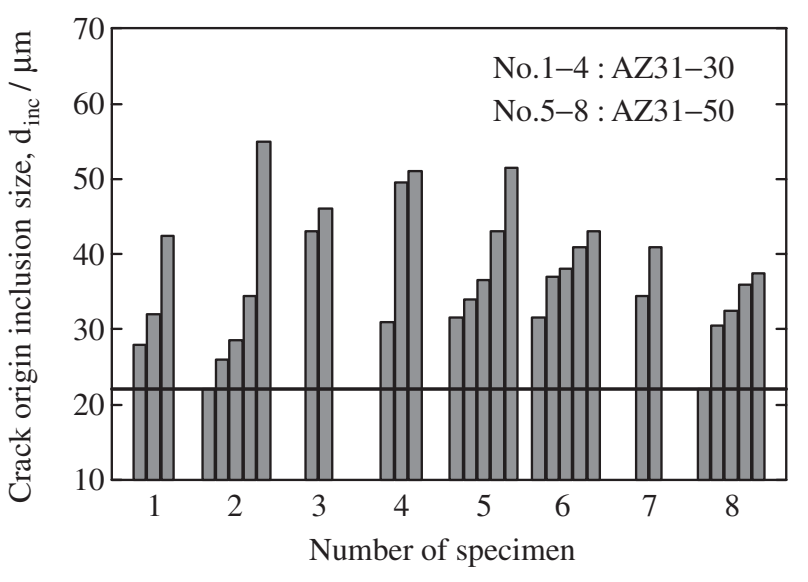

Fig. 7 Distribution of inclusion size as crack initiation sites.

\section{Discussion}

\subsection{Propagation behaviors of micro cracks}

The relationship between the crack propagation rate $\mathrm{d} a / \mathrm{d} N$ and the stress intensity factor range $\Delta K$ obtained from the results of Fig. 6 were shown in Fig. 8(a). The value of $\Delta K$ was calculated in the case of rotating bending loading from the equation by Y. Murakami. ${ }^{11)}$ From the figure, the relations in the both alloys showed almost similar tendency. Figure 8(b) shows the approximate curves of the relations of 

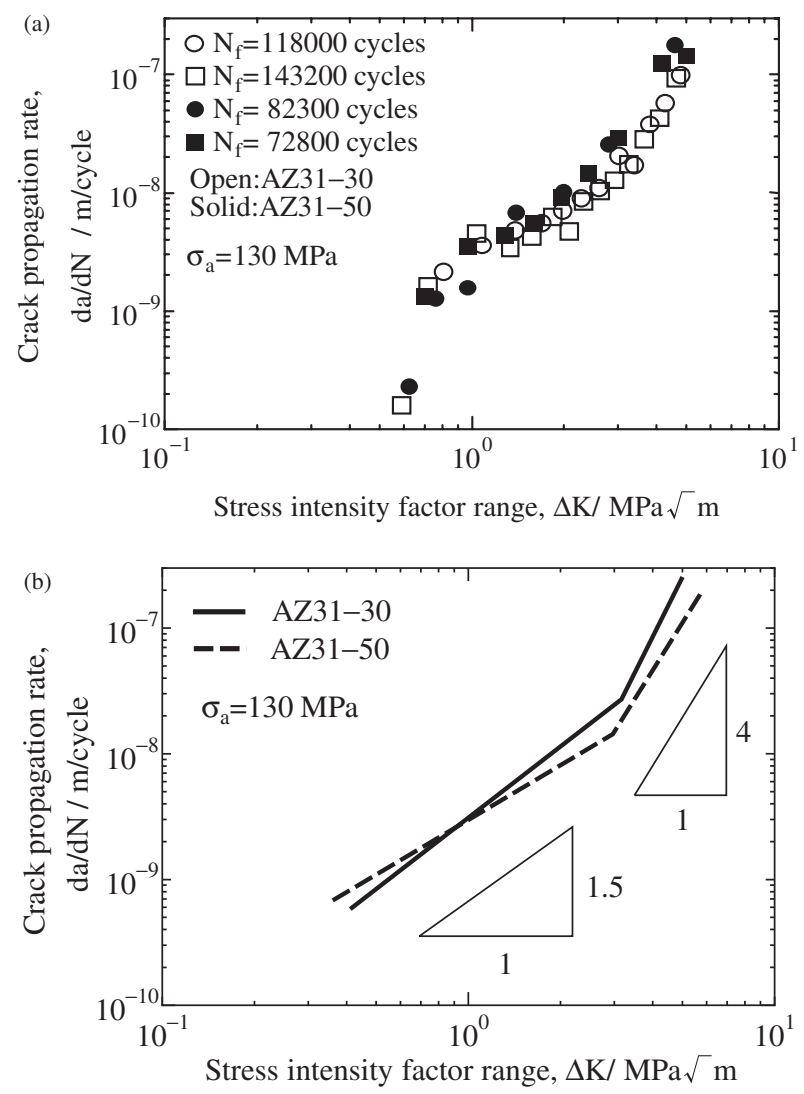

Fig. 8 Relation between crack propagation rate $\mathrm{d} a / \mathrm{d} N$ and stress intensity factor range $\Delta K$.

Fig. 8(a). From the curves, the relations between $\mathrm{d} a / \mathrm{d} N$ and $\Delta K$ showed clear bending point. The bending point of the relation between $\mathrm{d} a / \mathrm{d} N$ and $\Delta K$ had been reported by $\mathrm{K}$. Tokaji et al. ${ }^{8)}$

The value of the $\Delta K$ at the bending point of the relation between $\mathrm{d} a / \mathrm{d} N$ and $\Delta K$ in the present study was about $3 \mathrm{MPa} \sqrt{m}$, and the crack depth at the value of $\Delta K$ was about $450 \mu \mathrm{m}$. The depth coincided almost with the transition depth from the intense rough area to the comparable flat area of the fracture surface by SEM observation. As the transition of the fracture morphology was assumed to relate closely to the crack propagation behaviors, the plastic zone size of the crack tip at the bending point in the relation of $\mathrm{d} a / \mathrm{d} N-\Delta K$ was discussed. The relation between the plastic zone size $r_{\mathrm{p}}$ and the $\Delta K$ is expressed as the eq. (1). ${ }^{12)}$

$$
r_{\mathrm{p}}=(1 / 2 \pi)\left(\Delta K / \sigma_{\mathrm{y}}\right)^{2}
$$

where, the plastic zone size $r_{\mathrm{p}}$ was obtained as about $38 \mu \mathrm{m}$ by substituting the value of the $\Delta K=3 \mathrm{MPa} \sqrt{m}$ at the bending point of the relation $\mathrm{d} a / \mathrm{d} N-\Delta K$ and the average value of the $0.2 \%$ proof stress $(193.5 \mathrm{MPa})$ in both alloys as the yield stress into the eq. (1). As the value was intermediate between the grain sizes of the AZ31-30 $(29 \mu \mathrm{m})$ and the AZ31-50 $(47 \mu \mathrm{m})$, it was assumed that the transition of the fracture surface morphology was depended on the mutual relation between the plastic zone size and the grain size. As the magnesium alloys is hcp lattice structure and has fewer slip system comparing with those of bcc and fcc lattice structures, the propagation path of fatigue cracks is influ-
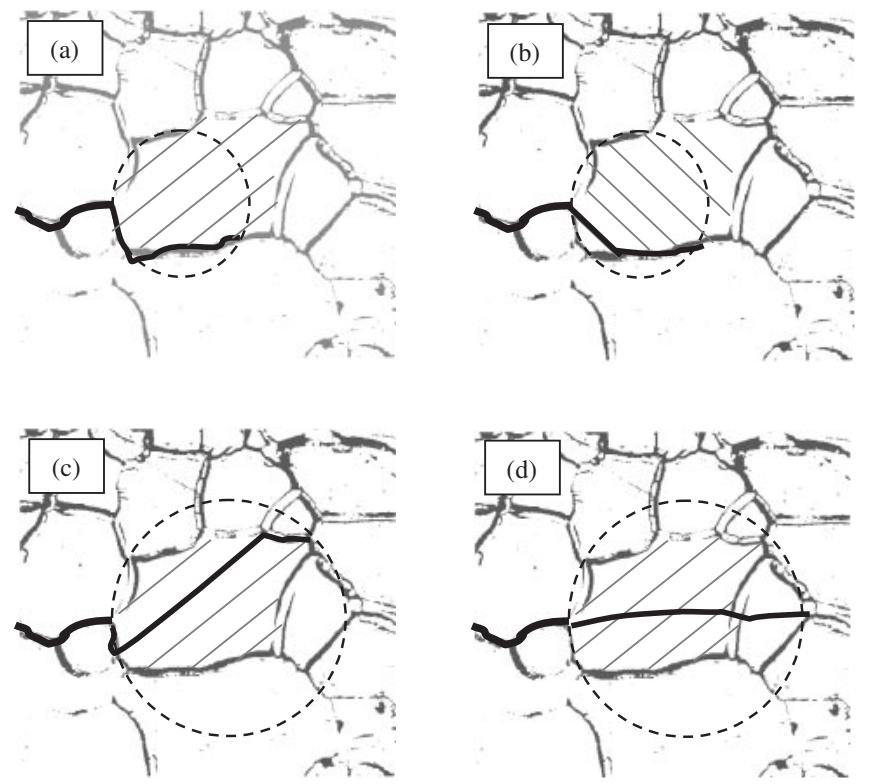

Fig. 9 Schematic drawings of crack propagation path and plastic zone size at the crack tip.

enced severely by the slip plane direction at the crack tip.

Figure 9 shows schematic drawing of the crack propagation paths and the plastic zone size. Figures 9(a) and (b) show the case which the plastic zone size are smaller than the grain size, on the other hand, Figs. 9(c) and (d) show the case which the plastic zone size are larger than the grain size. In the former case, as the slip deformation in the grain on the crack tip doesn't occur, then the crack propagates to the grain boundary. Occasionally, the crack might pass temporarily in the grain as an exception as shown in Fig. 9(b). However, as the case of the crack passing in the grain might be rare, then the crack path became strong winding along the grain boundary, and it is assumed that the fracture surface showed the severe rough morphology as the results. On the other hand, in the latter case, the fatigue crack propagates transgranular along the slip plane [Fig. 9(c)] or with cleavage fracturing [Fig. 9(d)], and it is assumed that the fracture surface showed comparable flat morphology as the results.

\subsection{Micro crack propagation behavior and microstruc- ture}

In order to discuss the relation between surface crack propagation behaviors and microstructures, the surface crack propagation paths were observed in full detail until the crack length reached to about 10 times of the average grain size by means of replica observation method. The specimen surface area for the observation was etched after taking away from the fatigue machine when the crack length reached to about 10 times of the average grain size. The investigation was performed at the stress amplitude of $130 \mathrm{MPa}$. The replication photographs of both alloys and the relation between $\mathrm{d} a / \mathrm{d} N$ and the crack length are shown in Figs. 10(a) and (b).

The crack initiation sites were inclusions in both alloys. The crack propagation paths in the early stage were manly grain boundary in both alloys, and the propagation rate dropping was observed when the crack propagated into the inside of grains. The crack propagated with strong winding 

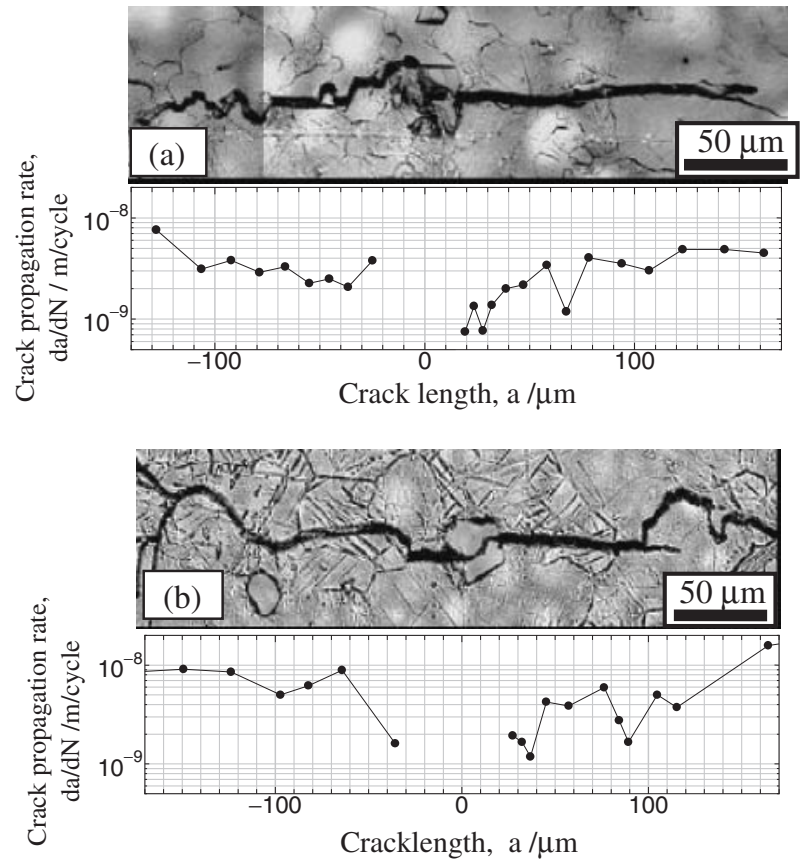

Fig. 10 Microscopic observation and crack propagation rate of small surface fatigue cracks.

along the grain boundary, and the degree of the crack winding of the AZ31-50 of the large grain size showed larger tendency comparing with that of the AZ31-30 of the smaller grain size. Because the strong winding stopped temporarily the crack propagation, the slope of the $\mathrm{d} a / \mathrm{d} N-\Delta K$ relation in the lower $\Delta K$ regime became lower comparing with that in the larger $\Delta K$ regime as shown in Fig. 8.

\subsection{Fatigue life evaluation}

It became clear that the crack initiation sites were inclusions near surface from the replica observation results, and the crack propagation behaviors were followed in the relation $\mathrm{d} a / \mathrm{d} N-\Delta K$ from the initiation of cracks to the final fracture. Therefore, the fatigue life evaluation was attempted from the relation of Paris's law $\mathrm{d} a / \mathrm{d} N-\Delta K$ and the inclusion size. The integrated regime of the crack length was taken from the inclusion size as the crack initiation sites to the crack length of final fracture. The inclusion sizes of the crack initiation sites were taken as 23 and $55 \mu \mathrm{m}$ from Fig. 7. The crack length of final fracture was taken as $630 \mu \mathrm{m}$ as assumed from the relation of the surface crack length observed by final fracture and the relative number of cycles $N / N_{\mathrm{f}}$ as shown in Fig. 11. And Paris's law used for integration was taken as the eq. (2) before the bending point and was taken the eq. (3) after the bending point, because the relation $\mathrm{d} a / \mathrm{d} N-\Delta K$ showed the bending point at the $\Delta K=3 \mathrm{MPa} \sqrt{m}$ as shown in Fig. 8(b). Moreover, aspect ratios $\beta(=c / a)$ of the surface crack were discussed in cases of $\beta=1.0$ and 0.8 ,where $\mathrm{c}$ is a crack depth and a is a half length of surface crack.

$$
\begin{aligned}
& \mathrm{d} a / \mathrm{d} N=3.5 \times 10^{-9} \Delta K^{1.5} \\
& \mathrm{~d} a / \mathrm{d} N=2.4 \times 10^{-10} \Delta K^{4.0}
\end{aligned}
$$

The estimated results of the fatigue lives are shown in

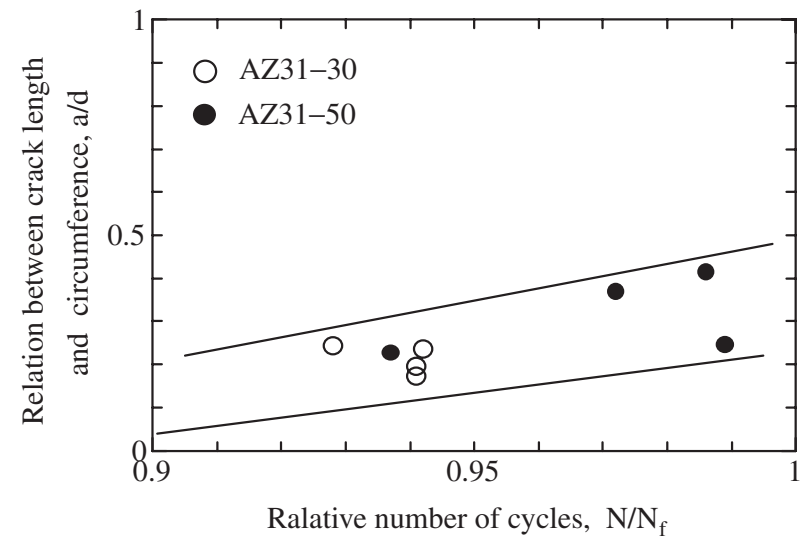

Fig. 11 Estimation of surface crack length at just before the fracture.

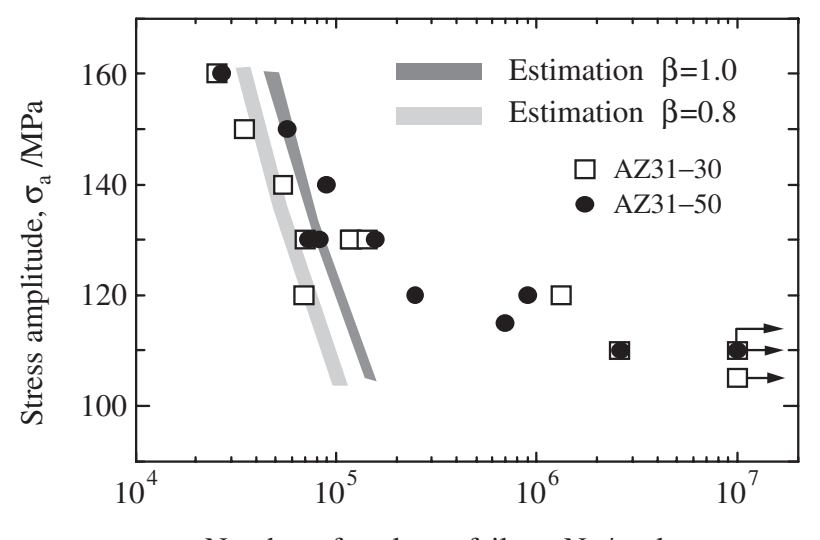

Number of cycles to failure, $\mathrm{N}_{\mathrm{f}}$ /cycles

Fig. 12 Results of fatigue life estimation.

Fig. 12. The fatigue lives of the higher stress amplitude level agreed with the experimental results. However, in the lower stress amplitude level near the fatigue limit, the estimated lives were shorter than those of the experimental data. In the case of the lower stress amplitude level near the fatigue limit, as the initial stress intensity factor range obtained by the inclusion size seemed to be about the threshold value of the relation $\mathrm{d} a / \mathrm{d} N-\Delta K$ in Fig. 8(a), then the real crack propagation rate might be lower than those of the evaluated law by the eq. (2).

\section{Conclusion}

High cycle fatigue tests in rotating bending loading have been carried out on extruded AZ31 magnesium alloys with two kinds of grain size. The main results obtained are summarized as follows,

(1) There were no clear difference in the fatigue property such as the fatigue strength, the crack initiation and propagation behaviors in two alloys with differences in grain size of about $20 \mu \mathrm{m}$.

(2) All of the crack initiation sites of two alloys were inclusions near surface and the size was distributed in the range of 23 to $55 \mu \mathrm{m}$.

(3) There was the bending point in the relation $\mathrm{d} a / \mathrm{d} N-$ $\Delta K$ at about $\Delta K=3 \mathrm{MPa} \sqrt{m}$. The reason showed the 
bending point was assumed that when the plastic zone size at the crack tip became larger than the average grain size, the crack propagated preferentially into the inside of grains from the grain boundary.

(4) The $\mathrm{d} a / \mathrm{d} N-\Delta K$ relations were expressed approximately as compositions of Paris's law with two different slopes. The fatigue life estimation from the inclusion size as the crack initiation sites and Paris's law with two slopes agreed well with the experimental results in the higher stress amplitude level.

(5) In order to improve the fatigue property in the extruded magnesium alloys, it needs to reduce the number and the size of inclusions. And also, in order to improve the fatigue life of the alloys, it is effective to control the micro crack propagation. For controlling the micro crack propagation, grain refinement is not always effective in magnesium alloys.

\section{REFERENCES}

1) Y. Murakami and K. Kamei: Non-Ferrous Metallic Materials (Asakura shoten, Tokyo, 1978)

2) T. S. Shih, W. S. Liu and Y. J. Chen: Mater. Sci. Eng. A 325 (2002) $152-162$.

3) H. Kato and T. Tozawa: J. Jpn. Inst. Light Metals 31 (1981) 240-247.

4) H. Kato and T. Tozawa: J. Jpn. Inst. Light Metals 32 (1982) 473-478.

5) Z. B. Sajuri, Y. Miyashita and Y. Mutoh: J. Jpn. Inst. Light Metals 51 (2002) 151-166.

6) K. Tokaji, T. Kamakura, N. Hasegawa and T. Tsuboi: J. Soc. Mater. Sci. Jpn. 52 (2003) 821-826.

7) M. Kamakura, K. Tokaji, Y. Ishizumi and N. Hasegawa: J. Soc. Mater. Sci. Jpn. 53 (2004) 1371-1377.

8) K. Tokaji, M. Kamakura, Y. Ishizuka and N. Hasegawa: Inst. J. Fatigue 26 (2004) 1217-1377.

9) N. Nan, S. Ishihara, T. Goshima and R. Nakanishi: Scripta Mater. 50 (2004) 429-434.

10) T. Mukai, M. Yamanoi, H. Watanabe and K. Higashi: Scripta Mater. 45 (2001) 89-94.

11) Y. Murakami: Stress Intensity Factors Handbook (Pergamon Press, U.K., 1987) pp. 657.

12) A. J. McEvily and Z. Yang: Met. Trans. A 21A (1990) 2717-2727. 